\title{
Fibreoptic bronchoscopy: effect of multiple bronchialo biopsies on diagnostic yield in bronchial carcinoma
}

\author{
ANDREW R GELLERT, ROBIN M RUDD, GAURI SINHA, DUNCAN M GEDDES
}

From the London Chest Hospital, London

ABSTRACT The findings in bronchial biopsy specimens obtained at fibreoptic bronchoscopy in $271_{\dot{\omega}}^{\times}$ patients with bronchial carcinoma were reviewed. Fifty-nine per cent of 703 specimens taken ${ }_{i}^{-}$ from the site of bronchoscopically visible tumours in 215 patients provided evidence of car-os cinoma. Unequivocal histological evidence of carcinoma was obtained in $78.6 \%$ of the $215^{\circ}$ patients with visible tumours. When only one biopsy specimen was taken evidence of carcinoma은 was obtained in $65.2 \%$ of cases. At least five biopsy specimens were required to provide a greater than $90 \%$ probability of obtaining at least one positive sample. The anatomical site of the tumouro had no significant effect on the proportion of biopsy specimens that were positive or the fre- $-\frac{\mathbb{\Phi}}{\mathbb{D}}$ quency of obtaining at least one positive sample. When extrinsic bronchial compression was the $\frac{\overline{7}}{6}$ only visible abnormality evidence of carcinoma was obtained by bronchial biopsy in $26.8 \%$ of $56^{\Phi}$ cases.

For the diagnosis of bronchial carcinoma the fibreoptic bronchoscope has a wider visual range ${ }^{1}$ than the rigid bronchoscope, and gives a higher rate of positive biopsy specimens when tumour is visible ${ }^{2}$ and a greater accuracy of cell type prediction. ${ }^{3}$ But histological interpretation of individual bronchial biopsy specimens obtained through the fibreoptic bronchoscope may be difficult because they are smaller than those obtained through the rigid bronchoscope, and because they may be crushed during withdrawal through the biopsy channel of the instrument. Rudd et $a^{3}$ suggested that the greater accuracy of prediction of carcinoma cell type by fibreoptic bronchial biopsies might be attributable to the fact that a larger number of biopsy samples is usually taken during fibreoptic bronchoscopy than during rigid bronchoscopy.

It is generally recommended that multiple biopsy specimens should be taken during fibreoptic bronchoscopy but the optimal number for the diagnosis of carcinoma has not been defined. This study examines the relation between the number of biopsy samples taken during fibreoptic bronchoscopy and the frequency of obtaining histological evidence of carcinoma when an endobronchial lesion is seen and when the only visible abnormality is extrinsic bronchial compression.

Reprints will not be available from the authors.

\section{Methods}

CASE SELECTION

Records of fibreoptic bronchoscopies performed aष्ठ the London Chest Hospital during 1978-81 were examined. Two hundred and fifteen cases were? identified in which an endobronchial lesion thought to represent tumour was seen, and in which biopsyo specimens were taken from the tumour. In all 215 cases the bronchoscopic appearances were of fleshy tumour or raised mucosal nodules. A further $5 \widetilde{\infty}$ cases were identified in which the only visible ${ }_{\sigma}^{\times}$ abnormality was extrinsic bronchial compression. and in which bronchial biopsy specimens were takeng from the site of compression. In all 271 cases a diag 3 nosis of bronchial carcinoma was confirmed, byo either histological or cytological evidence or, in 82 cases where this was not obtained, by clinical ant radiological features and by the subsequent clinica $\mathrm{F}$. course. For each of 271 cases identified the anatomer ical site of the lesion and the number of biopsies taken from it were noted.

BRONCHOSCOPIC AND HISTOLOGICAL

TECHNIQUES

The bronchoscopies were performed transnasally under local anaesthesia with an Olympus BFB3 fibreoptic bronchoscope. Biopsies were performe $f$ with Olympus forceps. Specimens were fixed in for malin, and paraffin sections from each of three level 
through each biopsy sample were stained with haematoxylin and eosin. Additional stains for mucin were performed when required. The histological sections were re-examined by one pathologist (GS), who determined the number of biopsy specimens offered for examination at each bronchoscopy. Where the bronchoscopist had recorded the number of specimens taken this was usually the same as the number found by the pathologist, but where a discrepancy existed the number determined by the pathologist was used in this study. The number of specimens showing unequivocal evidence of carcinoma was determined. The cell type was identified as squamous-cell, adenocarcinoma, oat-cell, or large-cell undifferentiated. This classification is based on that proposed by the World Health Organisation. $^{4}$

STATISTICAL ANALYSIS

Proportions were compared by the $\chi^{2}$ test.

\section{Results}

PROPORTION OF BIOPSIES SHOWING CARCINOMA IN PATIENTS WITH VISIBLE TUMOUR

Seven hundred and three biopsy specimens were taken from 215 patients in whom endobronchial lesions were seen. Four hundred and sixteen $(59.2 \%)$ of the samples showed evidence of bronchial carcinoma. The number of biopsy specimens taken in a single case varied from one to seven. Table 1 shows the proportion of cases in which each

Table 1 Proportions of the total of 215 cases in which different numbers of biopsy specimens were taken

\begin{tabular}{ll}
\hline No of specimens & No $(\%)$ of cases \\
\hline 1 & $23(10 \cdot 7)$ \\
2 & $40(18 \cdot 6)$ \\
3 & $65(30 \cdot 2)$ \\
4 & $48(22 \cdot 3)$ \\
5 & $23(10 \cdot 7)$ \\
6 & $14(6 \cdot 5)$ \\
7 & $2(1 \cdot 0)$ \\
\hline
\end{tabular}

number of specimens was taken. The modal number taken was three and in $71.4 \%$ of cases from two to four specimens were taken. The proportion of biopsy specimens that were positive when different numbers of specimens were taken was not significantly different $(\mathrm{p}>0 \cdot 1)$, being around $60 \%$ in all cases.

FREQUENCY OF HISTOLOGICAL EVIDENCE OF CARCINOMA IN PATIENTS WITH VISIBLE TUMOUR Histological evidence of carcinoma was obtained in
$169(78.6 \%)$ of the 215 cases with visible tumour. Table 2 shows the relation between the number of biopsy specimens taken from visible tumour and the

Table 2 Estimated and observed frequencies of obtaining at least one positive biopsy specimen in relation to the number of specimens taken

\begin{tabular}{lll}
\hline No of specimens & $\begin{array}{l}\text { Estimated probability } \\
\text { of at least one positive } \\
\text { specimen (\%) }\end{array}$ & $\begin{array}{l}\text { Observed frequency of } \\
\text { at least one positive } \\
\text { specimen (\%) }\end{array}$ \\
\hline 1 & $59 \cdot 2$ & 65.2 \\
2 & 83.3 & 68.0 \\
3 & 93.2 & 75.4 \\
4 & 97.2 & 83.3 \\
5 & 98.9 & 96.0 \\
6 & 99.5 & 100.0 \\
7 & 99.8 & 100.0 \\
\hline
\end{tabular}

frequency of obtaining at least one specimen showing evidence of carcinoma. The frequency increased with the number of specimens taken from $65 \%$ with one specimen to more than $95 \%$ with five or more. The frequencies of obtaining at least one positive biopsy specimen were significantly different when different numbers of specimens were taken $(p<$ $0.05)$.

Overall the proportion of biopsy samples showing carcinoma was about the same regardless of the number taken. Each successive specimen might therefore be assumed to have an independent and equal chance of showing carcinoma. From this assumption the probability of obtaining at least one positive biopsy specimen can be calculated according to the number of specimens taken. The probability, $P_{n}$, of obtaining at least one positive specimen when $n$ specimens are taken is given by $P_{n}=1-$ $(1-p)^{n}$, where $p$ is the probability that a single specimen will be positive. Table 2 shows these estimated probabilities, on the assumption that the chance of a single sample being positive is $59.2 \%$, which was the observed proportion of total biopsy samples that were positive. These probabilities are compared with the observed frequency of obtaining at least one positive specimen. When only one biopsy specimen was taken the frequency of obtaining a positive was slightly higher than expected. With multiple specimens the observed frequency was less than the estimated probability of obtaining at least one positive specimen until six were taken.

EFFECTS OF CELL TYPE AND SITE OF LESION ON DIAGNOSTIC YIELD

Table 3 shows the proportions of biopsy specimens that were positive for each cell type. There was a trend towards a higher proportion of positive sam- 
Table 3 Proportion of biopsy specimens showing evidence of carcinoma for each cell type

\begin{tabular}{llll}
\hline Cell type & No of cases & $\begin{array}{l}\text { No of } \\
\text { specimens }\end{array}$ & $\begin{array}{l}\text { Percentage of } \\
\text { specimens } \\
\text { positive }\end{array}$ \\
\hline Oat-cell & 64 & 167 & 74.9 \\
Squamous-cell & 74 & 184 & $72 \cdot 4$ \\
Adenocarcinoma & 5 & 16 & $68 \cdot 8$ \\
Large-cell & 25 & 87 & $63 \cdot 2$ \\
\hline
\end{tabular}

ples in oat-cell carcinoma, but this did not reach statistical significance. The frequencies of obtaining at least one positive biopsy specimen could not be compared because the cell type was not known in most of the cases where all specimens were negative.

The anatomical site of the lesion had no significant effect on the proportion of biopsy specimens that were positive or the frequency of obtaining at least one positive specimen.

\section{RESULTS WHEN EXTRINSIC COMPRESSION WAS}

ONLY BRONCHOSCOPIC ABNORMALITY

One hundred and twenty-four biopsy samples were taken from 56 patients in whom the only bronchoscopic abnormality was extrinsic compression. Nearly a third $(30.6 \%)$ of the specimens showed evidence of carcinoma. The modal number of samples taken was one. Histological evidence of carcinoma was obtained in $15(26.8 \%)$ of the 56 cases. The frequency of obtaining at least one positive specimen increased from $21.1 \%$ to $33.3 \%$ when three or more biopsies were taken. There were very few cases in which more than three biopsies were taken. The cell type was oat-cell in 10 of the 15 cases, squamous in four and large-cell in one.

\section{Discussion}

The usual practice is to take multiple biopsy specimens from endobronchial lesions seen at fibreoptic bronchoscopy to provide adequate tissue for histological examination. Recent reviews of bronchoscopic techniques have suggested that at least three specimens should be taken, ${ }^{56}$ but the optimal number has not been established. The aim should be to avoid the unnecessary risk of haemorrhage and the waste of laboratory resources resulting from taking more samples than are required to maximise the diagnostic yield. We found that $59 \%$ of biopsy specimens showed evidence of carcinoma. If the probability of each successive specimen being positive was $59 \%$ the diagnostic yield would exceed $90 \%$ with three, but in practice the yield from three specimens was only $75 \%$ and five were required to achieve a yield exceeding $90 \%$.

Unequivocal evidence of carcinoma was obtained by bronchial biopsy in $78.6 \%$ of cases with tumour $\frac{\bar{\sigma}}{\bar{D}}$ visible at fibreoptic bronchoscopy. This yield is simi- $\frac{\vec{\sigma}}{\vec{\sigma}}$ lar to that of $71 \%$ reported by Kvale et al, ${ }^{7}$ but $\stackrel{\complement}{\circ}$ somewhat lower than those of $89 \%$ reported by $\%$ Knight and Clarke ${ }^{8}$ and $91 \%$ by Macdonald ${ }^{9}$ and by $\vec{\circ}$ Webb and Clarke. ${ }^{2}$ Knight and Clarke, ${ }^{8}$ however, included biopsy samples reported as "suggestive of $\vec{\omega}$ carcinoma" as positive, while Macdonald" and $\stackrel{\text { ? }}{\rightleftharpoons}$ Webb and Clarke ${ }^{2}$ did not state whether equivocal $\vec{x}$ reports were considered positive. Knight and $\omega_{\nu}$ Clarke $^{8}$ found that positive biopsy rates for visible 0 tumours improved over a period after the introduc- $\infty$ tion of fibreoptic bronchoscopy at their institu- + tion. We have found that bronchoscopists with greater $\frac{\circ}{7}$ experience obtain a histological diagnosis in a higher $\vec{A}$ proportion of cases with visible tumour. ${ }^{10}$ This factor $\mathbb{\mathscr { D }}$ may partly explain differences in positive biopsy $\underset{\mathbb{D}}{\stackrel{0}{0}}$ rates reported in different studies.

Brush biopsy samples and bronchial aspirates mayळ occasionally provide evidence of carcinoma when $\overrightarrow{\vec{\theta}}$ bronchial biopsy is negative. ${ }^{1112}$ Their interpreta- $\infty$ tion requires expert cytopathological opinion, which! is not available in many institutions. Even when such facilities are available the accuracy of prediction of cell type is lower by cytological than by histologicalo techniques. ${ }^{313}$

Distortion of bronchial anatomy by extrinsic $\stackrel{\mathbb{2}}{\stackrel{\perp}{\varrho}}$ compression without any visible abnormality of the $\overrightarrow{\vec{A}}$ bronchial mucosa is a common bronchoscopic 3 finding in bronchial carcinoma. It is common practice to take mucosal biopsy specimens from the site? of compression but there is little information about the diagnostic yield in such circumstances. We found응 that histological evidence of carcinoma was obtained $\stackrel{0}{\times}$ in $26.8 \%$ of such cases. The proportion of biopsyo specimens that were positive was lower than when: an endobronchial lesion was found, but fewerô specimens per case were taken when. only extrinsic compression was seen and this may have contributed음 to the lower frequency of obtaining at least one posi- $\rightarrow$ tive sample.

When tumour was visible there was a trend towards a higher proportion of positive biopsy sam - r ples in oat-cell carcinoma than in other cell types, $N$ although this did not reach statistical significance. N This was also true for cases where only extrinsico compression was seen.

We conclude that at least five bronchial biopsy specimens should be taken to maximise the chance? of obtaining histological evidence of carcinomato when an endobronchial tumour or extrinsic bronchial compression is seen at fibreoptic broncho- $\Omega$ scopy. 


\section{References}

' Kovnat DM, Rath GS, Anderson WM, Snider GL. Maximum extent of visualisation of the bronchial tree by flexible fibreoptic bronchoscopy. Am Rev Respir Dis 1974;110:88-90.

${ }^{2}$ Webb J, Clarke SW. A comparison of biopsy results using rigid and fibreoptic bronchoscopes. $\mathrm{Br} J \mathrm{Dis}$ Chest 1980;74:81-3.

${ }^{3}$ Rudd RM, Gellert AR, Boldy DAR, Studdy PR, Pearson MC, Geddes DM. Predictive value of bronchial carcinoma cell type diagnosis by fibreoptic and rigid bronchoscopic bronchial biopsy and percutaneous aspiration lung biopsy. Thorax 1981;37:462-5.

${ }^{4}$ Kreyberg L. Histological typing of lung tumours. Geneva: World Health Organisation, 1967.

${ }^{5}$ Kvale PA. Collection and preparation of bronchoscopic specimens. Chest 1978;73, suppl:707-12.

- Knight RK. Bronchoscopy and other biopsy techniques. In: Emerson $\mathrm{P}$, ed. Thoracic medicine. London: Butterworths, 1981:189-219.

${ }^{7}$ Kvale PA, Bode FR, Kini S. Diagnostic accuracy in lung cancer: comparison of techniques used in association with flexible fibreoptic bronchoscopy. Chest 1976;69:752-7.

${ }^{8}$ Knight RK, Clarke SW. An analysis of the first 300 fibreoptic bronchoscopies at the Brompton Hospital. Br J Dis Chest 1979;73:113-20.

${ }^{9}$ Macdonald JB. Fibreoptic bronchoscopy today: a review of 255 cases. $\mathrm{Br}$ Med J 1975;iii:753-7.

${ }^{10}$ Gellert AR, Rudd RM, Sinha G, Geddes DM. Fibreoptic bronchoscopy: effect of experience of operator on diagnostic yield of bronchial biopsy in bronchial carcinoma. $\mathrm{Br} J$ Dis Chest (in press).

$"$ Zavala DC. Diagnostic fibreoptic bronchoscopy: techniques and results of biopsy in 600 patients. Chest 1975;68:12-9.

12 Lyall JRW, Summers GD, O'Brien IM, Bateman NT, Pike CP, Braimbridge MV. Sequential brush biopsy and conventional biopsy: direct comparison of diagnostic sensitivity in lung malignancy. Thorax 1980;35:929-31.

${ }^{13}$ Payne CR, Hadfield JW, Stovin PGI, Barker V, Heard B, Stark JE. Diagnostic accuracy of cytology and biopsy in primary bronchial carcinoma. J Clin Pathol 1981;34:773-8. 